Honorata Sosnowska*

Paweł Zawiślak**

\title{
DIFFERENCES BETWEEN JURORS IN CLASSICAL MUSIC COMPETITIONS: THE MCDM AND NETWORK THEORY APPROACHES
}

DOI: $10.22367 / \operatorname{mcdm} .2019 .14 .06$

\begin{abstract}
This paper analyses the voting in two of the major international classical music competitions, which were held recently, viz. the International Henryk Wieniawski Violin Competition and the International Chopin Piano Competition, as well as the hypothesis, raised in some media reports, that there were juror cliques in the Wieniawski Competition. Network theory is used to compare the rankings of the two Chopin competitions. Jurors are nodes and they are linked if the correlation between the ordered list of competitors, as measured by the Kendall rank correlation coefficient, exceeds a given threshold value. The obtained networks were found linked in the case of the Chopin Competition, but disconnected in the case of the Wieniawski Competition. The results indicate that there may have been cliques in the Wieniawski Competition, but not in the Chopin Competition.

The problem can be descibed in MCDM terminology by labelling the contestants 'variants' and the jurors (or, more precisely, their musical preferences) - 'criteria'. The similarity of any two criteria is measured by correlating the orders of the alternatives (i.e. variants) that
\end{abstract}

* SGH Warsaw School of Economics, Department of Mathematics and Mathematical Economics, Warsaw, Poland, e-mail: honorata@sgh.waw.pl, ORCID: 0000-0001-8249-2368.

** SGH Warsaw School of Economics, Department of Mathematics and Mathematical Economics, Warsaw, Poland, e-mail: pzawis@sgh.waw.pl, ORCID: 0000-0002-5297-7644. 
result from applying them. The problem of juror cliques is thereby transformed into one of finding groups of criteria that are similar in the case of these variants.

Keywords: correlation network, minimal spanning tree, voting method.

\section{Introduction}

Two of the worlds' major classical music competitions are held in Poland every five years, viz. the International Chopin Piano Competition and the International Henryk Wieniawski Violin Competition. This paper analyses the most recent competitions, viz. the $16^{\text {th }}(2010)$ and $17^{\text {th }}(2015)$ Chopin Competitions and the 2016 Wieniawski Competition. The voting methodology is analysed using social choice methods in Sosnowska (2013, 2017). Each competition has its own specific voting methodology. Analyses of classical music competitions are not all that common, especially when compared with e.g. sports competitions. There are a few papers that connect music, sport and art in their assessment of expert competitions, e.g.: Rzążewski et al. (2014), Gambarelli (2008), Gambarelli et al. (2012), Przybysz (2000) and Flores and Ginsburgh (1996). These papers also briefly analyse ski-jumping, figure skating, wrestling, the Triennale Grafiki, the Prime Minister's Prize, and European grants competitions. Voting systems in classical music competitions, sports competitions and grant competitions are similarly constructed and can be considered a special case of MCDM.

In a multi-stage classical music competition many voting methods are used prior to the decisive final stage, where some kind of ranking is usually employed. There were 10 contestants and 12 jurors in the final of the $16^{\text {th }}$ Chopin Competition (the voting methodology is described in Sosnowska (2013)) and 10 contestants and 17 jurors in the final of the $17^{\text {th }}$ Chopin Competition. The ranking was based on a distribution of 55 points on a scale $1-10$, so that only one contestant could get 10 points. In the most recent Wieniawski Competition there were 7 contestants and 13 jurors in the final. A reverse Borda count was used, i.e. the winner received 1 point. In each competition exceptions were made to the rules if a contestant was a student of a juror.

Sport competitions such as ski-jumping and figure skating are judged using a similar methodology. It therefore follows that any competition judged by experts can be analysed using a methodology similar to that applied in classical music competitions.

Both "Gazeta Wyborcza", one of Poland's most popular daily newspapers (Dębowska, 2016) and "Ruch Muzyczny" (Januszkiewicz and Choroś- 
ciak, 2016), the country's leading music journal, raised the possibility that the jurors of the most recent Wieniawski Competition formed cliques. This hypothesis is tested using network theory (see Jackson, 2006; Newman et al., 2010, 2006).

The paper is structured as follows: section 2 transforms the voting in classical music competitions into an MCDM problem, section 3 includes basic information about networks, section 4 applies network theory to analyse jury homogenity and section 5 presents the conclusions.

\section{Voting in classical music competitions as an MCDM problem}

The variants (also called alternatives) and the decision makers, as well as their characterizations and their decision-making methodologies have to be established first. The variants are the contestants and there are very few of them in the final of a competition. The variants are ranked according to certain criteria. A criterion is the musical preference of a particular juror. There are as many criteria as there are jurors. The variants can be weakly ordered according to each criterion. The criteria are aggregated into the final decision according to the voting method chosen.

One of the applications of MCDM is to detect and eliminate manipulation (Kontek and Sosnowska, 2018). The final result is the arithmetic mean of the jurors' votes (i.e. the scores given according to the criteria laid down). As mean values are very sensible to outliers, the mean is treated as a reference point and the distances between it and the individual results are measured. For this purpose, the Manhattan distance was selected from the many metrics available. This is applied in Kontek and Sosnowska (2018). The $20 \%$ of results that are most distant from the mean are then removed, i.e. the criteria farthest from the reference point are not considered, and the mean is recalculated. It has been shown both theoretically and empirically that this method is less prone to manipulation than the original method.

\section{Basic network theory}

This section briefly discusses the network concepts used in this paper. It begins by reviewing basic concepts, such as nodes and links, before shifting focus to weighted networks and correlation networks. Finally, the concept of minimal spanning trees is revisited. All these concepts are examinated in more detail in Newman et al. (2010, 2006), Horvath (2011) and West (2001). 


\section{$3.1 \quad$ Networks}

This paper considers mainly simply undirected networks. A (simple undirected) network is a pair $N=(N(N), L(N))$ consisting of a (usually finite) set $N(N)$ of nodes and a set $L(N)$ of links, where every link $l \in L(N)$ is a subset of $N(N)$ and consists of two (different) elements. Networks are often called graphs in the literature whereas nodes and links - vertices and edges, sites and bonds, or actors and ties, respectively.

The degree of a node is the number of links for which it is an endpoint.

A path in a network is a finite sequence $\left(i_{0}, i_{1}, \ldots, i_{k}\right)$ of nodes, such that every two consecutive nodes form a link. A network is connected if there is a path $\left(i=i_{0}, i_{1}, \ldots, i_{k}=j\right)$ connecting every two nodes $i$ and $j$. A connected component of a network is its maximal (in the sense of inclusion) connected subnetwork. A tree of $n$ nodes is a connected network with $n-1$ links.

\subsection{Weighted networks and correlation networks}

Let $N$ be a network, and assume that there exists a map $w: L(N) \rightarrow \mathbb{R}$. The triple $(N(N), L(N), w)$ is called a weighted network.

Consider a family $\left\{X_{s}: s \in S\right\}$ of variables and a threshold coefficient $\rho$. A correlation network $N$ can be constructed as follows. $S$ is the set $N(N)$ of nodes. The set $L(N)$ consists of the subsets $\{s, t\} \subset S$, such that $s \neq t$ and $\left|\operatorname{corr}\left(X_{s}, X_{t}\right)\right| \geq \rho$. This network is a weighted network whose weights are given by $w(l)=\operatorname{corr}\left(X_{s}, X_{t}\right)$ for all links $l=\{s, t\} \in L(N)$.

Weighted networks are used in biology (Horvath, 2011; Newman et al., 2006). Correlation networks are used in stock markets analysis (Górski et al., 2006; Cherifi et al., 2017) and in studies on the structural and functional organization of the human brain (Park and Friston, 2013).

\subsection{Minimal spanning trees}

Let $N$ be a connected network and let $w: L(N) \rightarrow \mathbb{R}$ be a weighting function. Assume that $w(l) \geq 0$ for every link $l \in L(N)$. A minimal spanning tree (MST) for $N$ is a subtree of $N$ containing all the nodes of $N$ such that the sum of the weights of all links is minimal.

MSTs were first used in Mantegna (1999) to indicate the most important (in some sense) currencies. 


\section{Voting in Polish classical music competitions - a network approach}

This section analyses the correlation networks of jurors' votes in final stages of the $15^{\text {th }}$ International Henryk Wieniawski Violin Competition and the $16^{\text {th }}$ and $17^{\text {th }}$ International Chopin Piano Competitions.

\section{1 $15^{\text {th }}$ International Henryk Wieniawski Violin Competition}

This section analyses the final results of the $15^{\text {th }}$ International Henryk Wieniawski Violin Competition. There were seven participants and eleven jurors, who had been using the inverse Borda count method (see Hołubiec and Mercik, 1994; Nurmi, 1987; Ordeshook, 1986 for a description of this method). The results are illustrated in Table 1.

These results were used to create a weighted network $W^{2016}$ as follows. The node set $N\left(W^{2016}\right)$ corresponds to the jurors and the link set $L\left(W^{2016}\right)$ comprises all links $\left\{J_{s}, J_{t}: s \neq t\right\}$ betweem them. For a link $l_{s t}$ connecting nodes $J_{s}$ and $J_{t}$, weight $w\left(l_{s t}\right)=w_{s t}$ is assigned, where $w_{s t}=\tau_{s t}$ is Kendall's $\tau$ coefficient (Abdi, 2007; Kendall, 1938, 1948) of the voting results of jurors $J_{s}$ and $J_{t}$ for $s, t=1,2, \ldots, 11$.

As this is a complete network on 11 nodes, it can be made more readable by creating networks $W_{p}^{2016}$ for $p=0.1,0.2,0.3,0.4,0.5$ such that links $l_{s t}$ with weights satisfying the condition $\left|w\left(l_{s t}\right)\right| \leq p$ are removed. These networks are presented in Figure 1.

Note that $W_{0.5}^{2016}$ has three groups of jurors $\left(\left\{J_{1}, J_{4}, J_{8}\right\},\left\{J_{2}, J_{3}, J_{6}, J_{7}\right\}\right.$ and $\left.\left\{J_{5}, J_{9}, J_{11}\right\}\right)$ such that the jurors voted coherently inside these groups, whereas jurors from the first group voted incoherently with the members of the second group (see Figure 4a).

\section{2 $16^{\text {th }}$ and $17^{\text {th }}$ International Chopin Piano Competitions}

This section examines the final results of the $16^{\text {th }}$ and $17^{\text {th }}$ International Chopin Piano Competitions. The voting methods employed are described in Sosnowska $(2013,2017)$. These results are illustrated in Table 2 and Table 3 , respectively.

In these cases the networks $C^{2010}, C_{p}^{2010}$ for $p=0.1,0.2,0.3,0.4,0.5,0.6$, $C^{2015}$ and $C_{p}^{2015}$ for $p=0.1,0.2,0.3,0.4,0.5,0.6,0.7,0.8$ are studied. These networks are constructed in a similar way to those analysed earlier. The Kendall $\tau$ coefficients are calculated by omiting unavailable data. The networks are presented in Figures 2 and 3, respectively. 
Note that although $C_{0.5}^{2010}$ and $C_{0.5}^{2015}$ are disconnected, they still have one main connected component. This means that the votes of individual jurors were not strongly mutually correlated. Networks $C_{p}^{2010}$ and $C_{p}^{2015}$ split for $p=0.6$ and $p=0.7$, respectively (Figures $2 \mathrm{~g}$ and $3 \mathrm{~h}$ ), but they still have the main connected components - core groups of jurors voting very coherently.

\subsection{Minimal spanning trees}

This section analyses the MSTs of the networks described above. Let $N$ be a correlation network. The weights of the links in this network are given by $w(l)=\operatorname{corr}\left(X_{s}, X_{t}\right)$ for $l=\{s, t\}$. For stock market networks, this correlation is measured by a Pearson correlation coefficient (Boddy and Smith, 2009).

As the correlation coefficient takes values from the interval $[-1,1]$, to determine the MST for $N$, the correlation coefficients need to be transformed into a metric given by $d_{s t}=\sqrt{2\left(1-\rho_{s t}\right)}$, where $\rho_{s t}$ is the Pearson correlation coefficient of the variables $X_{s}$ and $X_{t}$ (see Mantegna, 1999).

As Kendall's $\tau$ coefficient is used here, the Kendall distance (Abdi, 2007; Kendall, 1938, 1948) is used instead.

The minimal spanning trees for networks $W^{2016}, C^{2010}$ and $C^{2015}$ are presented in Figure 5.

Note that the nodes with the highest degree in MST of $W^{2016}$ are in the three main connected components in $W_{0.5}^{2016}$, whereas those with the highest degree in MSTs of $C^{2010}$ and $C^{2015}$ are in the same main connected component in $C_{0.6}^{2010}$ and $C_{0.8}^{2015}$, respectively (see Figures 4 and 5).

\subsection{Conclusions from the comparison of the networks}

A cursory inspection of the $W^{2016}$ and $C^{2010}$ and $C^{2015}$ networks is sufficient to conclude that they differ (see Figures 1a, 2a and 3a). The individual votes in the two Chopin Competitions were coherent (there were only a few pairs of jurors whose votes were negatively correlated), whereas those in the Wieniawski Competition were much more inconsistent.

We now focus on analysing the connectedness of the networks for different threshold values $p$. Only those links with positive weights (marked solid) are considered. This is because a positively weighted link indicates coherent voting on the part of the jurors who correspond to the nodes connected by it.

For $p=0.2$ networks $C_{0.2}^{2010}$ and $C_{0.2}^{2015}$ are connected (see Figures 2c and $3 \mathrm{c})$. For $p=0.3$ and $p=0.4$ networks $C_{0.3}^{2010}$ and $C_{0.4}^{2010}$ have two connected components (see Figures $2 \mathrm{~d}$ and $2 \mathrm{e}$ ), although one of them consists of a single node (the juror $M K$, who voted the most inconsistently), and 
networks $C_{0.3}^{2015}$ and $C_{0.4}^{2015}$ are connected (Figures $3 \mathrm{~d}$ and $3 \mathrm{e}$ ). For $p=0.5$, networks $C_{0.5}^{2010}$ and $C_{0.5}^{2015}$ have three and two connected components respectively (Figures 2f and 3f). Even though $C_{0.5}^{2010}$ and $C_{0.5}^{2015}$ are disconnected, they still have one main connected component, which implies that the votes of the individual jurors were not strongly correlated with the votes of others.

Networks $C_{p}^{2010}$ and $C_{p}^{2015}$ split for $p=0.6$ and $p=0.7$, respectively (Figures $2 \mathrm{~g}$ and $3 \mathrm{~h}$ ), but they still have the main connected components, i.e. core groups of jurors voting very coherently.

It should be noted that for $p>0.1$, networks $C_{p}^{2010}$ and $C_{p}^{2015}$ have no negatively weighted links. This implies that there were no strongly negative correlated votes amongst jurors during the Chopin Competitions in 2010 and 2015.

On the other hand, even though for $p<0.4$ networks $W_{p}^{2016}$ are connected and for $p=0.4$ network $W_{0.4}^{2016}$ has one main connected component (Figure 1), they have negatively weighted links. This interesting phenomenon can be observed for the threshold value $p=0.5 . W_{0.5}^{2016}$ has three groups of jurors $\left(\left\{J_{1}, J_{4}, J_{8}\right\},\left\{J_{2}, J_{3}, J_{6}, J_{7}\right\}\right.$ and $\left.\left\{J_{5}, J_{9}, J_{11}\right\}\right)$ such that amongst these groups jurors voted coherently, whereas jurors from the first group voted contrarily to the ones from the second group (see Figure 4a).

The analysis of the MSTs of networks $W^{2016}, C^{2010}$ and $C^{2015}$ concentrates on the degrees of nodes. The construction of the MST leads to the conclusion that a node (i.e. a juror) with a high degree in MST has many neighbours (other jurors) in the initial network that voted similarly. Therefore nodes with high degrees in MST can indicate the most influential jurors. In the present case, these influential jurors are $J_{1}, J_{7}$ and $J_{9}$ in $W^{2016}, K K$ and $D S T$ in $C^{2010}$, and $T D$ in $C^{2015}$ (see Figures 4 and 5). In the first network, jurors $J_{1}, J_{7}$ and $J_{9}$ are in the three groups mentioned above (Figure 4a), whereas jurors $K K$ and $D S T$ are in the same connected component: the second one (Figure 4b).

The nature of impact of the most influential jurors in $W^{2016}$ differs from that of the most influential jurors in $C^{2010}$ and $C^{2016}$. In the first case, the most influential jurors affect only jurors from their own groups, whereas in the second case, the most influential jurors affect almost all the others.

\section{Conclusions and recommendations for further research}

The voting results described above contain a great deal of information about the preferences of voters and their structure. The problem of voting can be described as an MCDM problem. Network theory can be applied to highlight the properties of networks constructed on the basis of jurors' votes. The 
obtained networks can be used to describe the homogeneity or heterogeneity of those votes.

\section{Acknowledgments}

While working on this paper, the second author was partially supported by the following SGH funds: KAE/S16/03/16, KAE/S17/BD, KAE/S18/BD and $\mathrm{KAE} / \mathrm{S} 18 / 08 / 18$.

All calculations and figures were prepared with $\mathrm{R} 3.4 .4$ ( $\mathrm{R}$ Core Team, 2019).

\section{References}

Abdi H. (2007), The Kendall Rank Correlation, [in:] N.J. Salkind (ed.), Encyclopedia of Measurement and Statistics, SAGE Publications, Thousand Oaks (CA).

Boddy R., Smith G. (2009), Statistical Methods in Practice: For Scientists and Technologists, Wiley, Chichester.

Cherifi H., Gaito S., Quattrociocchi W., Sala A. (eds.) (2017), Complex Networks \& Their Applications $V$, Proceedings of the 5th International Workshop on Complex Networks and their Applications, Springer, Cham.

Dębowska A.S. (2016), Konkurs Wieniawskiego 2016: Wewnętrzna wojna jurorów. Zwyciężczyni ledwo weszła do finału [2016 Wieniawski Competition. Internal Jury War. Winner Barely Makes Final], http://wyborcza.pl/7,113768,20925157,konkurswieniawskiego-2016-wewnetrzna-wojna-jurorow.html?disableRedirects $=$ true (16 September 2019).

Flores R., Ginsburgh V. (1996), The Queen Elisabeth Musical Competition: How fair is the final ranking, Journal of the Royal Statistical Society D-Sta, 45(1), 97-104.

Gambarelli G. (2008), The „Coherent Majority Average” for Juries' Evaluation Processes, Journal of Sports Sciences, 26, 1091-1095.

Gambarelli G., Iaquinta G., Piazza M. (2012), Anti-collusion Indices and Averages for Evaluation of Performances and Judges, Journal of Sports Sciences, 30, 411-417.

Górski A.Z., Dróżdż S., Kwapień J., Oświęcimka P. (2006), Complexity characteristics of currency networks, Acta Physica Polonica B, 37(11), 2987-2995.

Hołubiec J., Mercik J.W. (1994), Inside Voting Procedures, Accedo Verlagsgesellschaft, Munich.

Horvath S. (2011), Weighted Network Analysis: Applications in Genomics and Systems Biology, Springer Science \& Business Media, New York.

Jackson M. (2006), The Economics of Social Networks, [in:] R. Blundell, W. Newey, T. Persson (eds.), Advances in Economics \& Econometrics: Theory \& Applications, Ninth World Congress of the Econometric Society, Cambridge University Press, Cambridge, $1,1-56$.

Januszkiewicz M., Chorościak E. (2016), Wielka gra [Great game], Ruch Muzyczny, 11, 50-55.

Kendall M.G. (1938), A New Measure of Rank Correlation, Biometrika, 30(1-2), 81-93.

Kendall M.G. (1948), Rank Correlation Methods, Charles Griffin \& Company Limited, London. 
Kontek K., Sosnowska H. (2018), Specific Tastes or Cliques of Jurors?, https://papers.ssrn.com/sol3/papers.cfm?abstract_id=3297252, working paper.

Mantegna R.N. (1999), Hierarchical Structure in Financial Markets, The European Physical Journal B, 11(1), 193-197.

Newman M.E.J. (2010), Networks: An Introduction, Oxford University Press, Oxford.

Newman M.E.J., Barabási A.-L., Watts D. (2006), The Structure and Dynamics of Networks, Princeton University Press, Princeton.

Nurmi H. (1987), Comparing Voting Systems, D. Reidel Publishing Company, Dordrecht.

Ordeshook P. (1986), Game Theory and Political Theory, Cambridge University Press, Cambridge.

Park H.J., Friston K. (2013), Structural and Functional Brain Networks: From Connections to Cognition, Science, 342(6158), 1238411, 1-8.

Przybysz D. (2000), Agregowanie ocen sędziów sportowych jako przykład zbiorowego podejmowania decyzji [Aggregation of Sports Judges' Scores as an Example of Collective Decision Making], Studia Socjologiczne, 1-2, 105-136.

R Core Team (2019), R: A Language and Environment for Statistical Computing, Home page: http://www.R-project.org/.

Rzążewski K., Słomczyński W., Życzkowski K. (2014), Każdy głos się liczy [Every vote counts], Wydawnictwo Sejmowe, Warsaw.

Sosnowska H. (2013), The Rules for the Jury of the Fryderyk Chopin Piano Competition as a non Standard Voting Rule, Roczniki Kolegium Analiz Ekonomicznych, 32, 1-9.

Sosnowska H. (2017), Comparison of Voting Methods Used in Some Classical Music Competitions, [in:] N.T. Nguyen, R. Kowalczyk, J. Mercik (eds.), Transactions on Computational Collective Intelligence XXVII, LNCS (Lecture Notes in Computer Science 10480), Springer, 108-117.

West D.B. (2001), Introduction to Graph Theory, Second Edition, Prentice Hall, Upper Saddle River.

\section{Tables and Figures}

Table 1: Final results of the $15^{\text {th }}$ International Henryk Wieniawski Violin Competition

\begin{tabular}{|c|c|c|c|c|c|c|c|c|c|c|c|}
\hline & J1 & J2 & J3 & J4 & J5 & J6 & J7 & J8 & J9 & J10 & J11 \\
\hline A & 7 & 3 & 2 & 7 & 7 & 4 & 3 & 7 & 7 & 7 & 7 \\
\hline B & 4 & 7 & 7 & 2 & 2 & 7 & 7 & 2 & 5 & 6 & 5 \\
\hline C & 5 & 5 & 5 & 3 & 6 & 6 & 5 & 5 & 6 & 1 & 6 \\
\hline D & 3 & 6 & 4 & 5 & 1 & 5 & 4 & 4 & 3 & 5 & 1 \\
\hline E & 1 & 4 & 6 & 1 & 3 & 3 & 6 & 3 & 4 & 3 & 4 \\
\hline F & 6 & 2 & 1 & 6 & 4 & 2 & 1 & 6 & 1 & 2 & 2 \\
\hline G & 2 & 1 & 3 & 4 & 5 & 1 & 2 & 1 & 2 & 4 & 3 \\
\hline
\end{tabular}


Table 2: Final results of the $16^{\text {th }}$ International Chopin Piano Competition ( $s$ denotes that the participant was a student of a juror and was therefore not rated by that juror)

\begin{tabular}{|l|l|l|l|l|l|l|l|l|l|l|l|l|}
\hline & MA & DTS & BD & PE & FT & NF & AH & AJ & KK & MK & PP & KP \\
\hline A & 1 & 1 & 1 & 1 & 1 & 2 & 4 & 4 & 1 & 4 & 1 & 2 \\
\hline B & 2 & 2 & 3 & 9 & 4 & 2 & 6 & 7 & 2 & 10 & 6 & 1 \\
\hline C & 9 & 10 & 5 & 3 & 2 & 8 & 2 & 5 & 7 & 9 & 5 & 5 \\
\hline D & 2 & 3 & 2 & 4 & 3 & 3 & 3 & 2 & 1 & 1 & 2 & 4 \\
\hline E & 6 & 5 & 6 & 7 & 9 & 5 & 9 & 10 & 8 & 4 & 4 & 7 \\
\hline F & 3 & 4 & 7 & 8 & 6 & 6 & 10 & 6 & 7 & 6 & 7 & 6 \\
\hline $\mathbf{G}$ & 1 & 3 & 9 & 2 & 8 & 1 & 7 & 3 & 2 & 5 & 4 & 3 \\
\hline $\mathbf{H}$ & 10 & 10 & 10 & 5 & 10 & 9 & 8 & 9 & 9 & 8 & 10 & 9 \\
\hline $\mathbf{I}$ & 5 & 7 & 4 & 6 & 7 & 7 & 5 & 8 & 5 & 3 & 8 & 8 \\
\hline J & 4 & 1 & 1 & 1 & 3 & 4 & $s$ & 2 & 3 & 6 & 1 & 1 \\
\hline
\end{tabular}

Table 3: Final results of the $17^{\text {th }}$ International Chopin Piano Competition ( $s$ as in Table 2)

\begin{tabular}{|l|l|l|l|l|l|l|l|l|l|l|l|l|l|l|l|l|l|}
\hline & DA & MA & TD & AE & PE & NG & AH & AJ & GO & JO & PP & EP & KP & JR & WS & DY & $\mathbf{Y}$ \\
\hline A & 10 & 9 & 8 & 9 & 1 & 9 & 6 & 9 & 9 & 10 & 9 & 9 & 9 & 9 & 9 & 9 & 9 \\
\hline $\mathbf{B}$ & 2 & 4 & 2 & 3 & 3 & 2 & 6 & 3 & 6 & 1 & 1 & 1 & 1 & 5 & 1 & 5 & 4 \\
\hline $\mathbf{C}$ & 1 & 6 & 7 & 5 & 2 & 5 & 2 & 8 & 1 & 5 & 4 & 6 & 6 & 3 & 5 & 3 & 5 \\
\hline $\mathbf{D}$ & 7 & 4 & $s$ & 3 & 5 & 5 & 9 & 10 & 9 & 9 & 10 & 8 & 9 & 8 & 10 & 8 & 6 \\
\hline $\mathbf{E}$ & 9 & 5 & $s$ & 4 & 8 & 8 & 3 & 6 & 4 & 8 & 8 & 8 & 8 & 4 & 7 & 7 & 6 \\
\hline $\mathbf{F}$ & 4 & 4 & 1 & 3 & 4 & 2 & 2 & 5 & 2 & 6 & 5 & 2 & 4 & 2 & 5 & 4 & 3 \\
\hline $\mathbf{G}$ & 3 & 4 & 4 & 5 & 4 & 2 & 5 & 2 & 5 & 3 & 2 & 2 & 1 & 7 & 4 & 6 & 2 \\
\hline $\mathbf{H}$ & 8 & 9 & 8 & 9 & 8 & 10 & 7 & 6 & 8 & 7 & 6 & 7 & 10 & 9 & 8 & 9 & 9 \\
\hline $\mathbf{I}$ & 6 & 5 & 5 & 5 & 7 & 6 & 7 & 3 & 7 & 2 & 3 & 5 & 1 & 6 & 1 & 2 & 4 \\
\hline $\mathbf{J}$ & 5 & 5 & $s$ & 8 & 6 & 6 & 2 & 2 & 3 & 4 & 7 & 6 & 6 & 1 & 5 & 2 & 5 \\
\hline
\end{tabular}




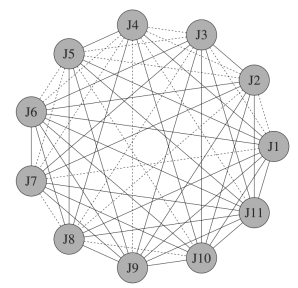

(a) Network $W^{2016}$

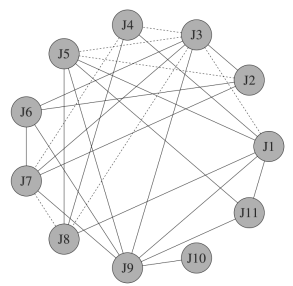

(d) Network $W_{0.3}^{2016}$

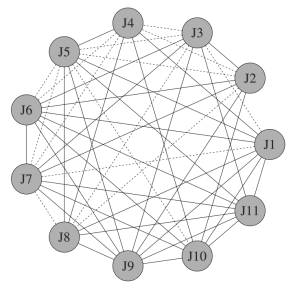

(b) Network $W_{0.1}^{2016}$

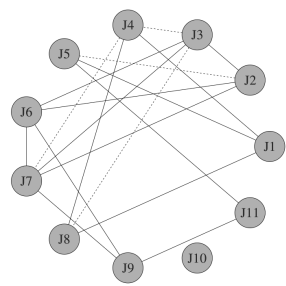

(e) Network $W_{0.4}^{2016}$

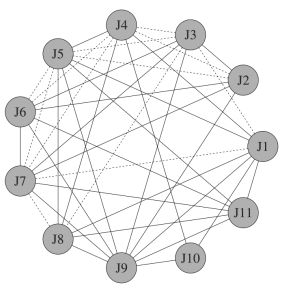

(c) Network $W_{0.2}^{2016}$

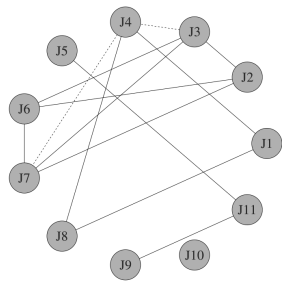

(f) Network $W_{0.5}^{2016}$

Figure 1: Vote correlation networks constructed from the final results of the $15^{\text {th }}$ International Henryk Wieniawski Violin Competition (solid - positive correlation, dashed - negative correlation) 


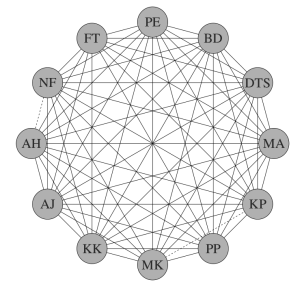

(a) Network $C^{2010}$

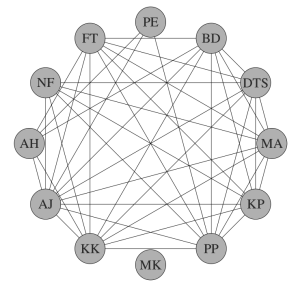

(d) Network $C_{0.3}^{2010}$

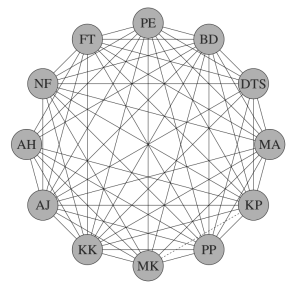

(b) Network $C_{0.1}^{2010}$

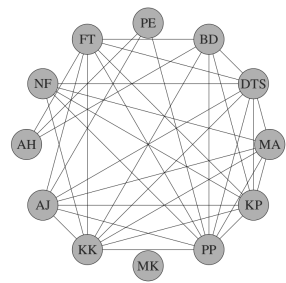

(e) Network $C_{0.4}^{2010}$

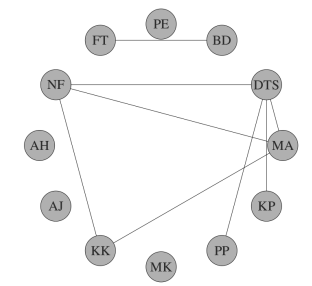

(g) Network $C_{0.6}^{2010}$

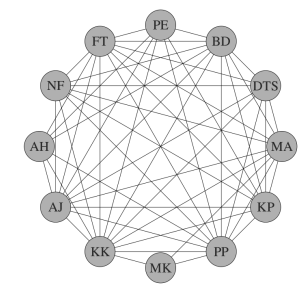

(c) Network $C_{0.2}^{2010}$

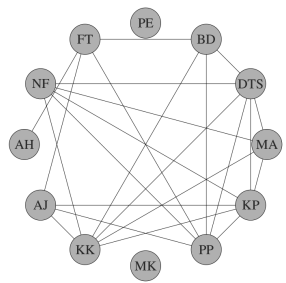

(f) Network $C_{0.5}^{2010}$

Figure 2: Vote correlation networks constructed from the final results of the $16^{\text {th }}$ International Chopin Piano Competition 


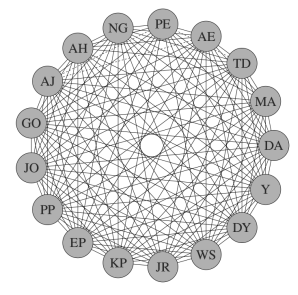

(a) Network $C^{2015}$

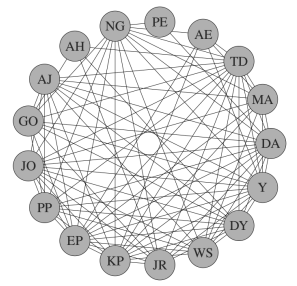

(d) Network $C_{0.3}^{2015}$

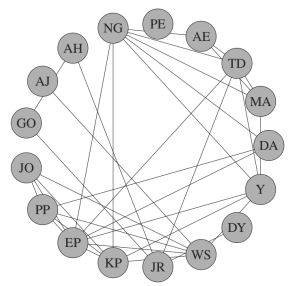

(g) Network $C_{0.6}^{2015}$

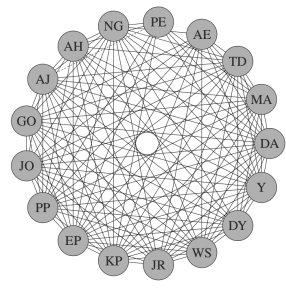

(b) Network $C_{0.1}^{2015}$

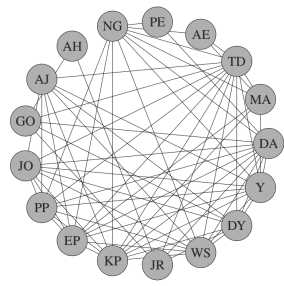

(e) Network $C_{0.4}^{2015}$

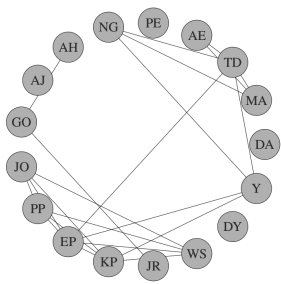

(h) Network $C_{0.7}^{2015}$

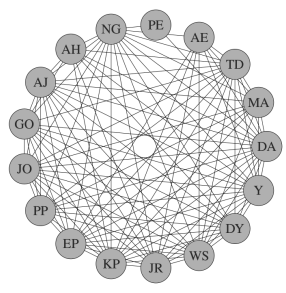

(c) Network $C_{0.2}^{2015}$

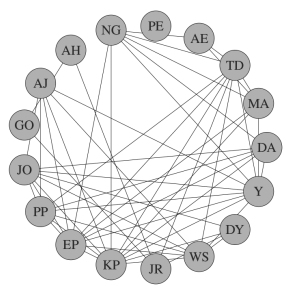

(f) Network $C_{0.5}^{2015}$

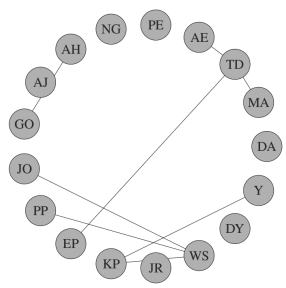

(i) Network $C_{0.8}^{2015}$

Figure 3: Vote correlation networks constructed from the final results of the $17^{\text {th }}$ International Chopin Piano Competition 

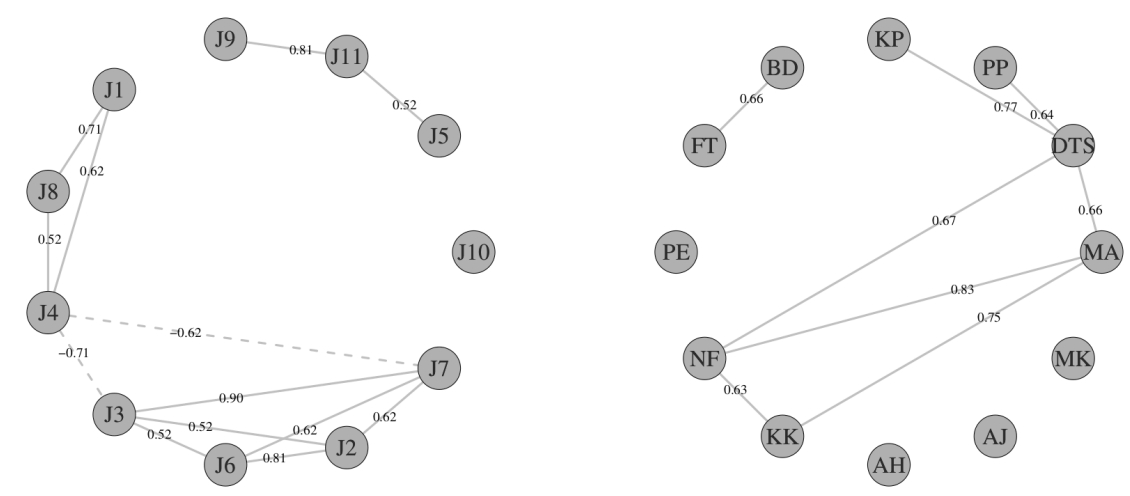

(a) Network $W_{0.5}^{2016}$

(b) Network $C_{0.6}^{2010}$

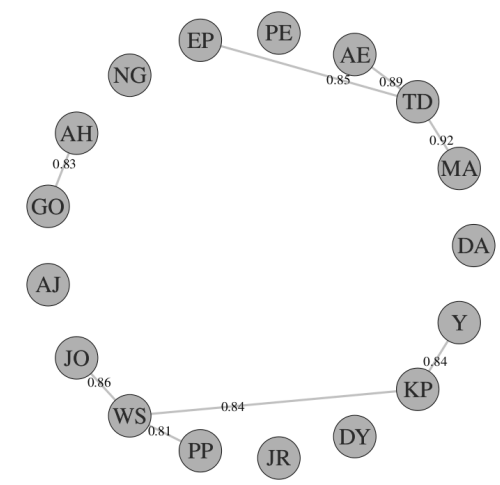

(c) Network $C_{0.8}^{2015}$

Figure 4: Networks of strongly correlated votes 

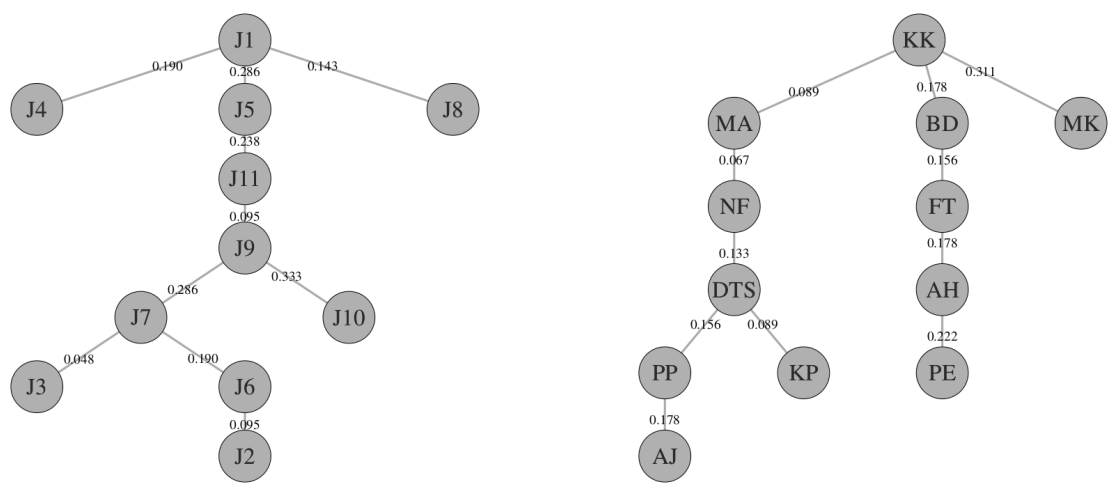

(a) MST of $W^{2016}$

(b) MST of $C^{2010}$

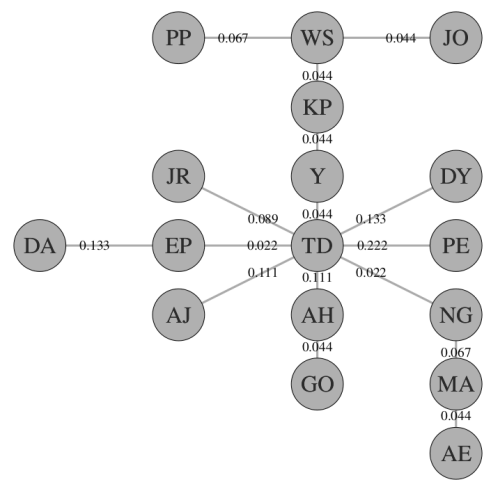

(c) MST of $C^{2015}$

Figure 5: Minimal spanning trees 